\title{
Reducing car use: changing attitudes or relocating? The influence of residential dissonance on travel behavior
}

\author{
Jonas De Vos, Ben Derudder, Veronique Van Acker, Frank Witlox
}

\begin{abstract}
Recent empirical studies have shown that attitudes and lifestyles are important determinants of travel behavior and modal choice. Less obvious and documented is that these 'soft variables' also influence other, non-travel related aspects such as residential choice. The result is that preferred residential neighborhoods not always match with the actual residential neighborhood. This residential dissonance (or mismatch) also has its influence on travel behavior since the preferred travel modes of dissonant residents may not be ideally available in their actual neighborhood. The main aim of this paper is to investigate the effect of residential dissonance on travel mode choice in Flanders, Belgium. Residential dissonance clearly affects the ability of people in realizing their preferred travel behavior, albeit in different ways for urban and rural residents.
\end{abstract}

\section{Keywords}

Residential dissonance, Travel behavior, Attitude, Residential self-selection, Travel mode choice, Flanders

\section{Introduction}

In most countries, car use has rapidly increased over the past decades. In Flanders, total travel distance by car has almost doubled in the period 1980-2008 (http://www.mobilit.fgov.be/). Because of negative consequences such as congestion and pollution, from the 1990s onwards, urban planners have tried to solve this problem by adapting the built environment. Concepts such as New Urbanism (in the USA) and the Compact City (in Europe) aim to reduce car use and travel distances by creating neighborhoods with a high density, a high diversity and a design oriented toward public transit and non-motorized travel (Cervero, 1996; Friedman et al., 1994; Schwanen and Mokhtarian, 2005a). The popularity of these concepts resulted in numerous empirical studies investigating the influence of the built environment on travel behavior, thereby statistically controlling for differences in socio-economic factors such as income, car ownership and household composition (Bagley and Mokhtarian, 2002; Chen et al., 2008; Mokhtarian and Cao, 2008; Van Acker et al., 2011a; van Wee et al., 2002). However, more recent research has shown that within homogeneous socio-economic groups different travel behavior can still be observed, indicating that not only 'objective' (or hard) variables, like the built environment and socio-economic factors, influence travel behavior, but that 
'Subjective' (or soft) variables should also be included in the analysis (Mokhtarian and Cao, 2008; Van Acker et al., 2011b; van Wee et al., 2002). According to various studies, personal lifestyles and attitudes have an important impact on travel behavior (Anable, 2005; Bagley and Mokhtarian, 2002; Kitamura et al., 1997; Schwanen and Mokhtarian, 2005a, 2005b; Steg, 2005; Steg et al., 2001). Certain lifestyles have a direct relationship with the mode choice of leisure trips. According to Van Acker et al. (2011b), car use is related to active and/or familyoriented lifestyles. Also, attitudes toward travel modes influence the mode choice: a positive stance toward a certain mode of transportation will result in a higher use of that mode. However, attitudes will not only influence the mode choice but also the residential location choice. Individuals with an affinity toward a certain kind of travel often choose a residential location that enables them to travel as much as possible with their preferred travel mode (Handy et al., 2005). A person who prefers public transit, for instance, often has an affinity for urban residential neighborhoods, as public transit is best organized in these urban areas (Bhat and Guo, 2007; Cao et al., 2007; Chen et al., 2008; Schwanen and Mokhtarian, 2005b; van Wee, 2009; van Wee et al., 2002). However, such a residential self-selection process is not always the case. Certain elements, such as income or distance to work, can constrain the residential location choice and might thus result in a dissonance between the actual and preferred residential neighborhood. This residential dissonance can have an impact on travel behavior since the preferred transportation modes of dissonant residents are not ideally available in their residential neighborhood. Or, in other words, the actual travel behavior of dissonant residents might not match with their preferred way of travelling. This paper analyzes the residential dissonance in Flanders, Belgium; it examines the influence of both the residential neighborhood and preferences toward neighborhoods on travel mode choice and observes what the consequences are on the capability of dissonant residents in realizing their preferred travel behavior. Furthermore, initiatives to reduce residential dissonance, in order to decrease car use, are being put forward.

The remainder of this paper is organized as follows. Section 2 reviews the literature on residential neighborhood type dissonance (or mismatch). Section 3 discusses the data and methods used. Results are presented in Section 4 and discussed in Section 5. Finally, our major conclusions are presented in Section 6.

\section{Dissonance between actual and preferred residential neighborhood}

\subsection{Causes of residential dissonance}

There can be many reasons for a mismatch between the actual and preferred residential neighborhood as the residential location choice is based on many different factors (e.g., physical neighborhood preferences). Households trade off these factors and, in theory, the neighborhood with the largest utility will be chosen. However, due to constraints such as income and distance to work, not all spatial preferences can be realized. In that case, the actual residential neighborhood chosen will differ from the preferred, optimal residential neighborhood; hence, a dissonance occurs. This mismatch is generally higher for households with low incomes as they often cannot afford their preferred residential location (Naess, 2005; 
Schwanen and Mokhtarian, 2004). The residential neighborhood type dissonance can also result from varying preferences within households. Since the residential location choice is a household decision, disagreements between members of the same household can cause a residential dissonance at the individual or household level (Molin et al., 1999). Furthermore, the size and the heterogeneity of the choice set of housing alternatives, available during the residential choice process, can also be associated with a residential dissonance. A large choice set may cause a very complicated trade-off between housing attributes resulting in a final location choice that is not the optimal one. If the choice set is too small, there is a possibility that the preferred residential neighborhood does not appear in the choice set. Major events in life cycles of individuals also cause a residential dissonance. The most obvious example of such an event is child birth. Households with children often have an affinity toward rural residential neighborhoods with green surroundings. Couples with young children residing in an urban neighborhood are probably more mismatched than couples without young children (Schwanen and Mokhtarian, 2004). The level of satisfaction with the current neighborhood also has an influence on residential dissonance. Households who are very satisfied with their residential neighborhood are less likely to relocate than households who are only slightly satisfied, even if these households do not live in the preferred residential neighborhood $(\mathrm{Oh}$, 2003; Speare, 1974).

\subsection{Influence of residential dissonance on travel behavior}

After having briefly specified what causes residential dissonance, we now focus on its influence on travel behavior. After all, mismatched residents might not be able to travel according to their travel preferences.

Schwanen and Mokhtarian (2005a) distinguish urban residents from suburban residents and individuals with urban land use preferences from individuals with suburban land use preferences. By doing so, four groups can be distinguished:

1. Urban consonants: urban residents with urban land use preferences;

2. Urban dissonants: urban residents with suburban land use preferences;

3. Suburban dissonants: suburban residents with urban land use preferences;

4. Suburban consonants: suburban residents with suburban land use preferences.

Residents from the second and third group are dealing with a residential dissonance. Schwanen and Mokhtarian (2005a) start their research with a basic hypothesis assuming that residents from these four groups fall on a continuous scale in terms of their average probability of travelling by car or by an alternative mode of transportation (Fig. 1). Suburban consonants mainly use private vehicles. Car use is lowest among urban consonants. Car use of mismatched residents lies between these two levels; urban dissonants seem to make somewhat less use of the car than suburban dissonants. The opposite can be found for travel by public transit or bicycling/walking. Urban consonants travel most with these car alternatives; suburban consonants make least use of these transportation modes. In their study, Schwanen 
and Mokhtarian (2005a) confirmed this continuous transition of travel behavior from urban consonants to suburban consonants.

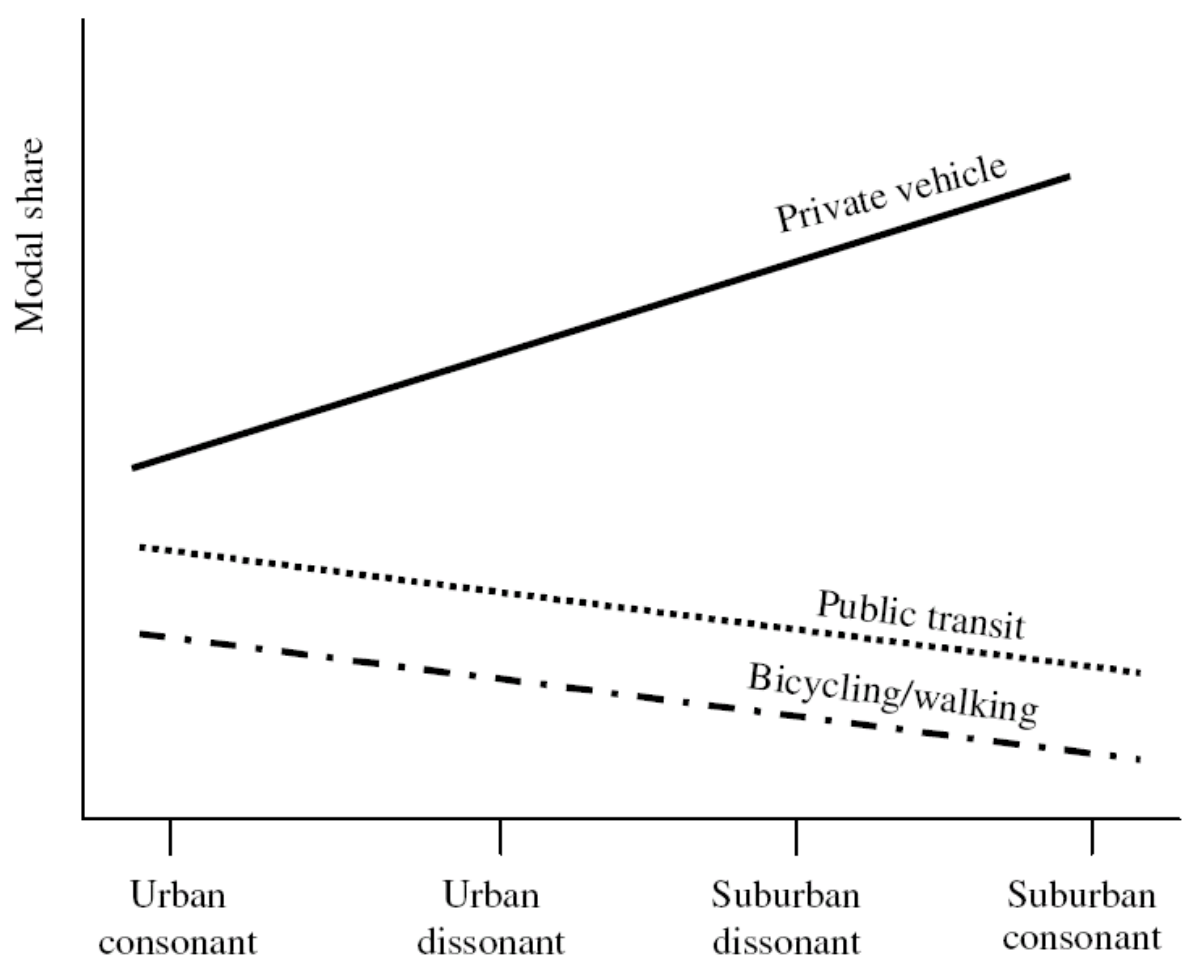

Fig. 1. Hypothesized continuum of actual and preferred residential neighborhood type and travel mode choice (Source: Schwanen and Mokhtarian, 2005a)

Schwanen and Mokhtarian (2005a) argue that the impact of residential dissonance is larger for suburban residents than for urban residents. Mismatched suburbanites are often forced to travel with a private vehicle, partly because public transit networks are not fine-grained in suburban neighborhoods. Mismatched urbanites, on the other hand, travel more with private vehicle than other urban residents. Urban dissonants are consequently more capable of realizing their preferred travel behavior than suburban dissonants (Schwanen and Mokhtarian 2005a, 2005b). Bagley and Mokhtarian (2002), however, claim that both urban dissonants and suburban dissonants have to adjust their travel behavior. In both cases, the built environment can impose restrictions on the travel mode choice. A suburban dissonant will often be forced to travel by car. An urban dissonant, on the other hand, will often have to make use of alternative transportation modes due to traffic congestion and expensive and limited parking places within urban neighborhoods. 


\section{Data and Methods}

The preceding literature review shows how residential dissonance influences travel behavior. The question now is to which extent residential dissonance occurs for Flemish respondents and how this dissonance influences their travel mode choice.

\subsection{Data}

The data used for this study comprise information about opinions and habits concerning leisure activities and mobility. The original survey (2007), on lifestyle and mobility, was (mainly) distributed among staff members and students of the University of Antwerp and the Faculty of Sciences at Ghent University (Van Acker et al., 2011a, 2011b). Despite efforts to obtain a well-balanced sample, respondents with a college or university degree are heavily overrepresented in the sample (66.2\%). Besides highly-educated respondents, women, married or cohabiting people, individuals with a high income and younger people are also overrepresented. Most respondents have, within their household, access to a car (average car ownership: 1.4 / household) or bicycle (average bicycle ownership: 3.3 / household); 68.6\% of the respondents has a stopping-place for bus, tram or subway within $750 \mathrm{~m}$ of their dwelling, almost $10 \%$ has a railway station near their dwelling (Table 1). In total, 2363 persons completed the survey of which 1657 were retained after data cleaning. Although the survey was not designed to question residential self-selection and spatial dissonance, it does offer information on the stance of respondents toward transportation modes.

Table 1. Socio-economic factors and the accessibility of transportation modes of respondents ${ }^{1}$

\begin{tabular}{l|lc:lc}
\hline Gender & Male & $40.7 \%$ & Female & $59.3 \%$ \\
Marital status & Single & $25.5 \%$ & Married/Cohabiting & $74.5 \%$ \\
Education & Low & $33.8 \%$ & High & $66.2 \%$ \\
Age (years) & $<20: 9.1 \%$ & $20-29: 55.4 \%$ & $30-39: 16.1 \%$ & $\geq 40: 19.4 \%$ \\
Monthly personal income & Low $(<1500 €)$ & $31.4 \%$ & High $(\geq 1500 €)$ & $68.6 \%$ \\
Possession driving license & Yes & $81.1 \%$ & No & $18.9 \%$ \\
Season ticket public transit & Yes & $41.7 \%$ & No & $58.3 \%$ \\
Household car possession & $0: 14.8 \%$ & $1: 41.9 \%$ & $2: 34.9 \%$ & $>2: 8.3 \%$ \\
Household bicycle possession & $0: 4.1 \%$ & $1: 12.3 \%$ & $2: 23.9 \%$ & $>2: 59.3 \%$ \\
Access to a railway station & Yes & $9.9 \%$ & No & $90.1 \%$ \\
Access to bus, tram or subway & Yes & $68.6 \%$ & No & $31.4 \%$ \\
\hline
\end{tabular}

\footnotetext{
${ }^{1}$ High education= respondents with a college or university degree; Access to a transportation mode = railway station or stopping-place of bus, tram or subway within $750 \mathrm{~m}$ of the respondents' dwelling.
} 


\subsection{Methods}

\subsubsection{Residential dissonance indicators}

Four indicators provide information on residential dissonance in Flanders. The first indicator is a binary indicator that describes the presence or absence of residential dissonance. The second indicator reveals gradual differences in the dissonance between preferred and actual residential neighborhood. The last two indicators result from the combination of neighborhood satisfaction with the first two indicators. However, since residential selfselection assumes that travel related attitudes, among others, influence land use preferences, these preferences are achieved in an indirect way.

Before discussing these indicators, information about the actual and preferred residential neighborhood of the respondents is needed. Respondents are subdivided according to the actual neighborhood in urban and rural residents, based on the 'Spatial Structure Plan for Flanders' (Ministerie van de Vlaamse Gemeenschap, 1997). This spatial structure plan divides the Flemish municipalities into categories ranging from metropolitan areas to countryside. We consider respondents residing in metropolitan areas to small urban areas as urban residents and respondents residing outside such urban areas as rural residents. Note that this subdivision is rather crude and may have its shortcomings. Gradual differences in residential neighborhoods are not included in the analyses. Besides, the subdivision is based on administrative units which do not necessarily correspond with the actual built environment. Information about the preferred residential neighborhood is obtained based on opinions and habits concerning leisure locations and mobility, retained from the survey.

The first indicator is a straightforward measurement that examines the similarity between the preferred and actual residential neighborhood. The share of respondents dealing with a residential dissonance can be obtained in this way. The opinions and habits concerning leisure locations and mobility, retained from the survey, result in 118 variables. In order to obtain a factor that more or less unambiguously reflects the preference toward an urban or rural residential neighborhood, it is necessary to perform a factor analysis. ${ }^{2}$ The number of factors (principal axis factoring, promax rotation) is based on the scree plot and the eigenvalues larger than one, but mainly on the interpretation of the factors. Table 2 shows the results. ${ }^{3}$ Nine factors are retained, which explain $34.8 \%$ of the variance: Pro bicycling/walking; Car accessibility and -parking; Pro car; Pro travel; Environmentally aware; Pro public transit; Accessibility Bicycling/walking; Proximity of shops, bars,....

\footnotetext{
${ }^{2}$ The Bartlett test of sphericity $\left(\chi^{2}=75209 ; \mathrm{df}=6903 ; \mathrm{p}=0.00\right)$ illustrates a sufficient degree of correlation between at least two variables; or in other words the factor analysis is useful.

${ }^{3}$ In this research, variables with a factor loading between -0.2 and 0.2 are not retained in pattern matrices.
} 
Table 2. Pattern matrix of the first factor analysis ${ }^{4}$

\begin{tabular}{|c|c|c|c|c|c|c|c|c|c|}
\hline How do you perceive mobility? $\downarrow$ & $\begin{array}{c}\text { Pro } \\
\text { bicycling/ } \\
\text { walking }\end{array}$ & $\begin{array}{c}\text { Car } \\
\text { access- } \\
\text { ibility and } \\
\text {-parking }\end{array}$ & Pro car & Pro travel & $\begin{array}{c}\text { Environ- } \\
\text { mentally } \\
\text { aware }\end{array}$ & $\begin{array}{l}\text { Access- } \\
\text { ibility } \\
\text { public } \\
\text { transit }\end{array}$ & $\begin{array}{c}\text { Pro public } \\
\text { transit }\end{array}$ & $\begin{array}{c}\text { Access- } \\
\text { ibility } \\
\text { bicycling/ } \\
\text { walking }\end{array}$ & $\begin{array}{c}\text { Proximity } \\
\text { of shops, } \\
\text { bars, ... }\end{array}$ \\
\hline Typical aspect walking? healthy & 0.962 & & & & & & & & \\
\hline Typical aspect walking? cheap & 0.890 & & & & & & & & \\
\hline Typical aspect bicycling? environment-friendly & 0.886 & & & & & & & & \\
\hline Typical aspect walking? environment-friendly & 0.878 & & & & & & & & \\
\hline Typical aspect bicycling? healthy & 0.878 & & & & & & & & \\
\hline Typical aspect bicycling? cheap & 0.869 & & & & & & & & \\
\hline Typical aspect walking? relaxing & 0.609 & & & & & & & & \\
\hline Typical aspect walking? reliable & 0.549 & & & & & & & & \\
\hline Typical aspect bicycling? relaxing & 0.503 & & & & & & & & \\
\hline Typical aspect p.t.? activities during travel & 0.495 & & & & & & & & \\
\hline Typical aspect bicycling? flexible & 0.443 & & & & & & & & \\
\hline Typical aspect bicycling? reliable & 0.403 & & & & & & & & \\
\hline Typical aspect p.t.? safe & 0.351 & & & & & & 0.386 & & \\
\hline Typical aspect walking? safe & 0.314 & & & & & & & & \\
\hline Typical aspect walking? flexible & 0.216 & & & & & & & & \\
\hline Typical aspect p.t.? environment-friendly & 0.214 & & & & & 0.224 & 0.212 & & \\
\hline Important aspect part. s\&c? car accessibility & & 0.860 & & & & & & & \\
\hline Important aspect part. s\&c? sufficient parking place & & 0.796 & & & & & & & \\
\hline Important aspect spect. s\&c? car accessibility & & 0.647 & & & & & & & \\
\hline Important aspect spect. s\&c? sufficient parking place & & 0.592 & & & & & & & \\
\hline Important aspect part. s\&c? free parking place & & 0.530 & & & & & & & \\
\hline Typical aspect car? flexible & & & 0.652 & & & & & & \\
\hline Typical aspect car? reliable & & & 0.644 & & & & & & \\
\hline Typical aspect car? comfortable & & & 0.630 & & & & & & \\
\hline Typical aspect car? time saving & & & 0.538 & & & & & & \\
\hline Typical aspect car? privacy offering & & & 0.501 & & & & & & \\
\hline Typical aspect car? safe & & & 0.441 & & & & & & \\
\hline Typical aspect car? relaxing & & & 0.319 & & & & & & \\
\hline
\end{tabular}

${ }^{4}$ p.t. $=$ public transit; part. $s \& c=$ participating sport $\&$ culture; spect. $s \& c=$ spectating sport $\&$ culture; f,p\&n = forest, park $\&$ nature 


\begin{tabular}{|c|c|c|c|c|c|c|}
\hline Do you agree? I find travel annoying & -0.883 & & & & & \\
\hline Do you agree? I like to travel & 0.780 & & & & & \\
\hline Do you agree? Travelling is lost time & -0.624 & & & & & \\
\hline Do you agree? Reaching my destination is most important & -0.566 & & & & & \\
\hline Do you agree? Traffic makes me nervous & -0.343 & & & & & \\
\hline Do you agree? I like to explore new, unknown places & 0.306 & 0.220 & & & & \\
\hline Important aspect mode choice? environment-friendly & & 0.797 & & & & \\
\hline Important aspect mode choice? healthy & & 0.694 & & & & \\
\hline Do you agree? I can help solve traffic problems & & 0.653 & & & & \\
\hline Do you agree? The growth of car use causes problems & & 0.630 & & & & \\
\hline Important aspect mode choice? relaxing & & 0.333 & & & & \\
\hline Do you agree? Less car use has no sense & & -0.329 & & & & \\
\hline Do you agree? I may only use the car if it is necessary & & 0.287 & & & & \\
\hline Important aspect spect. s\&c? accessibility by p.t. & & & 0.749 & & & \\
\hline Important aspect part. s\&c? accessibility by p.t. & & & 0.743 & & & \\
\hline Important aspect visiting f,p\&n? accessibility by p.t. & & & 0.674 & & & \\
\hline Important aspect going out? accessibility by p.t. & & & 0.533 & & & \\
\hline Important aspect shopping? accessibility by p.t. & & & 0.449 & & & \\
\hline Typical aspect p.t.? comfortable & & & & 0.555 & & \\
\hline Typical aspect p.t.? relaxing & & & & 0.536 & & \\
\hline Typical aspect p.t.? reliable & & & & 0.494 & & \\
\hline Typical aspect p.t.? time saving & & & & 0.443 & & \\
\hline Typical aspect p.t.? flexible & & & & 0.397 & & \\
\hline Typical aspect p.t.? safe & & & & 0.386 & & \\
\hline Typical aspect p.t.? cheap & & & & 0.335 & & \\
\hline Typical aspect p.t.? privacy offering & & & & 0.259 & & \\
\hline Typical aspect p.t.? healthy & & & & 0.224 & & \\
\hline Important aspect mode choice? activities during travel & & & & 0.223 & & \\
\hline Important aspect spect. s\&c? accessibility on foot & & & & & 0.839 & \\
\hline Important aspect part. s\&c? accessibility on foot & & & & & 0.683 & \\
\hline Important aspect going out? accessibility on foot & & & & & 0.381 & \\
\hline Important aspect shopping? accessibility on foot & & & & & 0.377 & \\
\hline Important aspect visiting f,p\&n? accessibility on foot & & & & & 0.259 & \\
\hline Important aspect spect. s\&n? accessibility by bicycle & & & & & 0.220 & \\
\hline Important aspect spect. s\&c? proximity of shops, bars,.. & & & & & & 0.759 \\
\hline Important aspect part. s\&c? proximity of shops, bars,.. & & & & & & 0.669 \\
\hline Important aspect shopping? proximity of shops, bars,.. & & & & & & 0.532 \\
\hline Important aspect visiting f,p\&n? proximity of shops, bars,.. & & & & & & 0.522 \\
\hline Important aspect going out? proximity of shops, bars,.. & & & & & & 0.478 \\
\hline
\end{tabular}


None of the nine factors can be unambiguously related with a certain preference toward a residential neighborhood and some of the factors are correlated and consequently reflect a similar preference. ${ }^{5}$ Therefore, it seems useful to factor analyze the obtained factors in order to obtain a (second-order) factor that unambiguously reflects this preference (Arnau, 1998; Thomas, 1995). This second-order factor analysis results in two second-order factors which are clearly related with two opposite preferences: i.e., Pro car alternatives and Pro car (Table 3). ${ }^{6}$ The two second-order factors explain $48.8 \%$ of the variance. Comparable to the firstorder factor analysis, interpretation of these second-order factors is the most important determinant for the number of factors (principal axis factoring, promax rotation). The firstand second-order factor analysis explain $17.0 \%(34.8 \% * 48.8 \%)$ of the total variance. Although this seems quite low, $17.0 \%$ of total explained variance is rather high in comparison with other second-order factor analyses (Van Acker et al., 2011b). However, this indicates that also other elements, which are not included into the two second-order factors, influence these preferences.

Table 3. Pattern matrix of the second-order factor analysis

\begin{tabular}{|c|c|c|c|}
\hline First-order factor $\downarrow$ & Second-order factor $\rightarrow$ & $\begin{array}{c}\text { Pro car } \\
\text { alternatives }\end{array}$ & Pro car \\
\hline Accessibility public transit & & 0.822 & \\
\hline Pro public transit & & 0.603 & \\
\hline Accessibility bicycling/walking & & 0.467 & \\
\hline Proximity of shops, bars, ... & & 0.411 & \\
\hline Pro bicycling/walking & & 0.316 & \\
\hline Environmentally aware & & & -0.908 \\
\hline Pro car & & & 0.642 \\
\hline
\end{tabular}

Note that Pro car alternatives and Pro car are, to a certain extent, related with a preference toward residential neighborhoods. Respondents with a positive score on the first factor (Pro car alternatives) are more likely to have an affinity toward car alternatives, and as a consequence mostly prefer urban neighborhoods. Respondents with a positive score on the second factor (Pro car) are more likely to have an affinity toward car use, and in consequence mostly prefer rural neighborhoods. We retained the first factor in order to subdivide respondents into two groups: those respondents who prefer urban neighborhoods and those respondents who do not. The combination of these preferences with the actual residential

\footnotetext{
${ }^{5}$ Rotation procedures (such as promax rotation) can allow for oblique angles between factor dimensions, which results in correlated factors.

${ }^{6}$ The Bartlett test of sphericity shows that also this second-order factor analysis is useful $\left(\chi^{2}=3152 ; \mathrm{df}=36 ; \mathrm{p}=\right.$ $0.00)$.
} 
neighborhood of the respondents results, based on Schwanen and Mokhtarian (2005a), in four groups: urban consonants, urban dissonants, rural dissonants and rural consonants.

Although this first indicator gives a certain amount of information, a binary indicator is crude and does not reflect gradual changes. Therefore a second indicator is needed to reflect gradual changes in the dissonance between actual and preferred residential neighborhood. To this end, the scores of the respondents on the 'pro car alternatives' factor are standardized between -1 and 1 . To make this measure less sensitive to outliers, the $5^{\text {th }}$ and $95^{\text {th }}$ percentile are taken as the minimum and maximum scores on this factor. The respondents are then subdivided, based on these standardized values, in the following categories:

- respondents with a weak agreement or a weak difference between the actual and preferred residential neighborhood (absolute, standardized value: 0 - 0.25);

- respondents with a moderate agreement or a moderate difference between the actual and preferred residential neighborhood (absolute, standardized value: $0.25-0.5$ );

- respondents with a strong agreement or strong difference between the actual and preferred residential neighborhood (absolute, standardized value: 0.5 - 0.75);

- respondents with a very strong agreement or very strong difference between the actual and preferred residential neighborhood (absolute, standardized value: $0.75-1$ ).

The first two indicators already give a lot of information about the residential dissonance. However, the satisfaction of the residents with their current neighborhood, which is linked with residential dissonance, has not been taken into account. Therefore, it is necessary to conduct two additional indicators. The third and fourth indicator result from the combination of the neighborhood satisfaction with the first two indicators. To construct these indicators, neighborhood satisfaction is calculated based on seventeen statements concerning the attraction of the current neighborhood. Respondents were asked how satisfied they are with various aspects in their current neighborhood. A five-point Likert scale was presented to them, going from 'very satisfied' to 'absolutely not satisfied'. To diminish the effect of outliers, the $5^{\text {th }}$ and $95^{\text {th }}$ percentile are also taken as the minimum and maximum values. Based on the average score of each respondent on the Likert scale, the respondents are subdivided in four groups:

- respondents with a very high neighborhood satisfaction;

- respondents with a high neighborhood satisfaction;

- respondents with a low neighborhood satisfaction;

- respondents without neighborhood satisfaction.

The combination of this neighborhood satisfaction with the first two indicators creates two additional indicators. 


\subsubsection{Travel mode choice}

Respondents were asked to indicate which transportation modes (car, train, bus/tram/subway, bicycle or on foot) they generally use to reach locations of six leisure activities (shopping; going out; visiting family or friends; visiting forest, park or nature; participating a sport or culture activity; spectating a sport or culture activity). Respondents were able to select different travel modes for different leisure activities. In case a respondent selected a certain transportation mode for at least one of the six possible leisure trips, this respondent was listed as a user of that transportation mode. Leisure trips were chosen because of the assumption that mode choice is most free for such trips, especially compared to nondiscretionary trips such as commuting.

\section{Results}

\subsection{Nature and size of residential dissonance}

The results of the first indicator, are shown in Table 4. The large share of respondents with a residential dissonance (or mismatch) is striking. More than half of the respondents participating in this study $(51.4 \%)$ reside in a neighborhood that does not match with their preferred residential neighborhood. The large share of urban residents with rural preferences $(55.6 \%(=685 / 1231))$ is remarkable in comparison with the share of rural respondents with a residential dissonance $(39.2 \%(=167 / 426))$. This can be explained by the large share of respondents with rural land use preferences $(57.0 \%$ ), while only $25.7 \%$ of the respondents live in rural residential neighborhoods.

Table 4. The size of the residential dissonance

\begin{tabular}{lcc}
\hline & $\boldsymbol{N}$ & $\%$ \\
\hline Urban & 1231 & 74.3 \\
Rural & 426 & 25.7 \\
Total & 1657 & 100 \\
\hline Urban land use preference & 713 & 43.0 \\
Rural land use preference & 944 & 57.0 \\
Total & 1657 & 100 \\
\hline Urban consonant & 546 & 33.0 \\
Urban dissonant & 685 & 41.3 \\
Rural dissonant & 167 & 10.1 \\
Rural consonant & 259 & 15.6 \\
Total & 1657 & 100 \\
\hline Match & 805 & 48.6 \\
Mismatch & 852 & 51.4 \\
Total & 1657 & 100 \\
\hline
\end{tabular}




\subsection{Influence of residential dissonance on travel behavior}

Fig. 2 suggests that walking, bicycling and the use of public transit (especially bus, tram and subway) is mainly determined by attitudes and only in limited degree by the built environment. Respondents with urban land use preferences (urban consonants and rural dissonants) make considerably more use of these transportation modes than respondents with rural land use preferences (urban dissonants and rural consonants). Car use seems less liable to land use preferences. The built environment seems to have a considerable influence on this mode of transportation. Car use increases from urban consonants to rural consonants. A stagnation is noticeable between the urban dissonants and the rural dissonants. Respondents of these two groups will travel almost equally by car. Fig. 2 clearly shows that the car is the only travel mode where such a monotone trend is noticeable; a constant decreasing trend is not visible for the use of car alternatives. Rural dissonants tend to travel more with these modes than urban dissonants. This suggests that car use struggles with physical constraints in urban neighborhoods, such as congestion and parking problems. The use of car alternatives in rural neighborhoods, on the other hand, is only slightly hampered by physical constraints. In spite of longer travel distances and a built environment where it is less obvious to organize public transit, rural dissonants frequently travel by alternative travel modes. It seems that rural dissonants are more capable of realizing their preferred travel behavior than urban dissonants.

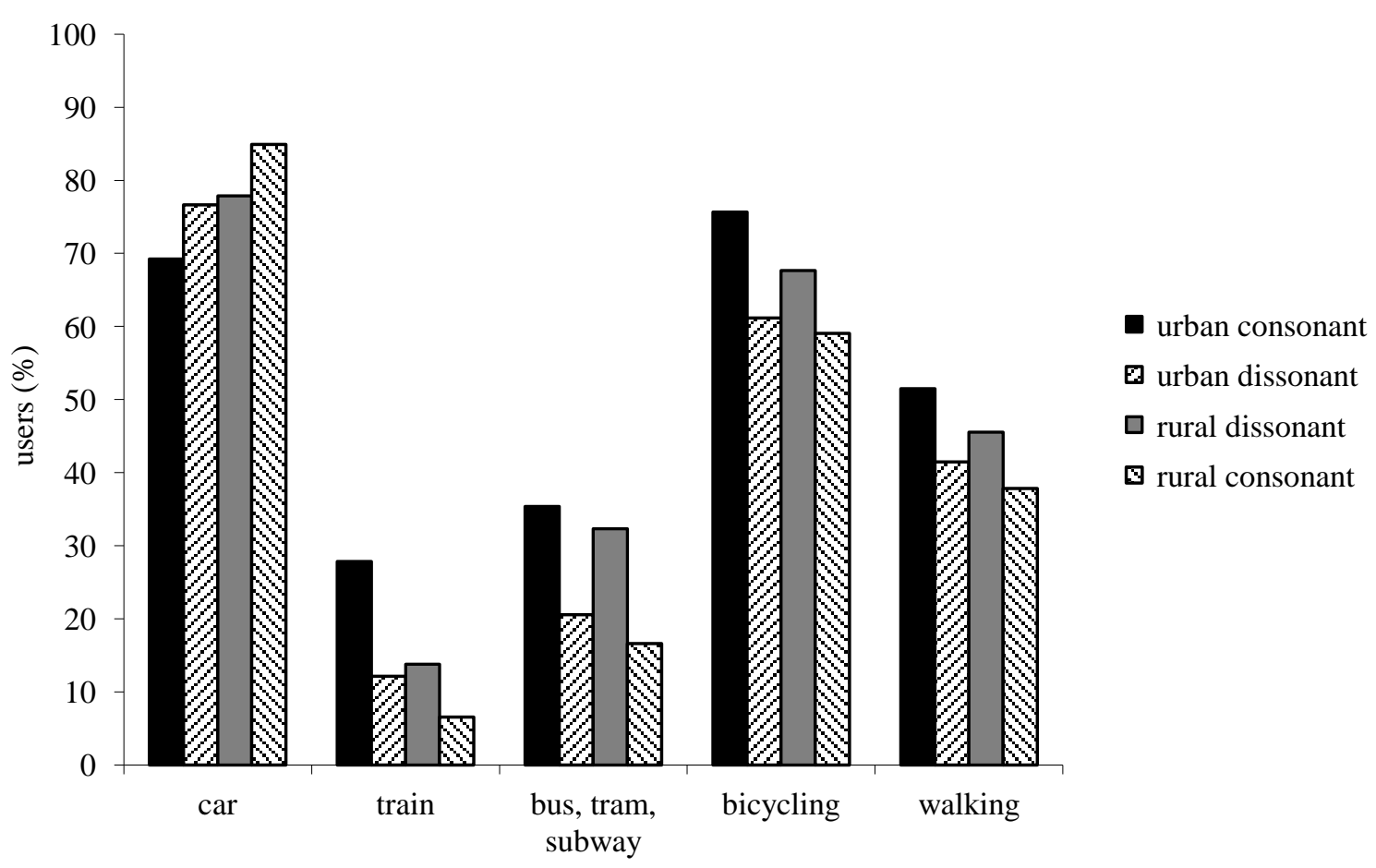

Fig. 2. Use of travel modes within groups of similar actual and preferred residential neighborhood 


\section{Discussion}

Travel mode choice can be determined both by the residential neighborhood and by preferences toward neighborhoods and travel modes. Walking, bicycling and the use of public transit can be mainly explained by travel-related attitudes and land use preferences. Car use seems to be more influenced by the built environment. This suggests that rural dissonants are more capable of realizing their preferred travel behavior than urban dissonants. In what follows we try to explain these findings.

\subsection{The causes and consequences of residential dissonance in Flanders}

Although fundamental differences in the sampling and measuring methods, a comparison of the current study with Schwanen and Mokhtarian's research (2004, 2005a, 2005b) in the San Francisco Bay Area reveals two remarkable findings concerning residential dissonance in Flanders:

- the large share of respondents who are dealing with a residential dissonance;

- the large ability of rural dissonants in realizing their preferred travel behavior, compared to urban dissonants.

The share of respondents with a dissonance between the actual and preferred residential neighborhood (51.4\%) is quite high. This can mainly be explained by the large group of urban residents $(74.3 \%)$ and large share of residents with rural land use preferences (57.0\%).

The applied land use planning and mobility policy can partly explain these results. Flanders is a strongly urbanized region where open spaces have become scarce over the last decades. A large part of the available space has already been built up by buildings, infrastructure and all sorts of other activities. This urban development dates back to the nineteenth century when a mobility policy of low-cost public transit combined with the realization of a fine-grained public transit network enabled people to reside further away from their work. This resulted in a strong suburbanization and a highly dispersed space. The supply of open spaces is consequently smaller than the demand by Flemish residents. Open spaces, which can only be found in rural areas, can therefore be considered as scarce goods. According to Van der Haegen et al. (1996), rural areas are, compared to urban areas, attractive places to reside because of less expensive housing prices and quiet, green surroundings. Research has also shown that youngsters prefer to reside in a quiet, green, safe and clean neighborhood. Most of them do not want to live in urban neighborhoods (Verhetsel and Witlox, 2006). These aspects can explain the large share of respondents with rural land use preferences and the larger share of mismatched urbanites in comparison with mismatched rural residents.

Rural dissonants travel a lot with car alternatives. Urban dissonants, on the other hand, are not able to travel by car as much as they desire. This suggests that rural dissonants are more capable of realizing their preferred travel behavior than urban dissonants. The mobilitysupporting policy in Flanders, dating back to the nineteenth century and also existing at 
present, can partly explain this phenomenon. The decree 'basic mobility', approved by the Flemish parliament in 2001, states that every Fleming has the right on a minimum supply of public transit. This decree (i.e., a law issued by the Flanders government) aims at providing a stopping-place for public transit within $750 \mathrm{~m}$ of the dwelling of $90 \%$ of the Flemings. The strongly urbanized area provides, next to relatively short travel distances which stimulate walking and bicycling, a large enough bearing surface to provide such a fine-grained public transit network. This can explain why rural dissonants succeed in realizing their preferred travel behavior. Urban dissonants, on the other hand, try to travel as much as possible by car. Increasing congestion and parking problems, however, prevent them from using their cars as frequently as they want to. These urban dissonants must rely on car alternatives more often than preferred. In other words, urban dissonants face more problems when travelling by car than rural dissonants when travelling by car alternatives.

\subsection{Influence of a reduced residential dissonance on travel behavior}

A reduction of the residential dissonance can have a positive influence on travel behavior. Two major opportunities for reducing this dissonance can be distinguished. A first way to reduce this mismatch is by relocating rural residents to urban neighborhoods. A second way to achieve such a reduction is by adapting travel-related attitudes (Schwanen and Mokhtarian, 2005a).

Schwanen and Mokhtarian (2005a) state that a relocation of mismatched non-urban residents to urban neighborhoods is the best way to reduce residential dissonance. These residents have an affinity toward alternative modes of transportation. In non-urban neighborhoods they are often forced to use the car. As urban residents, however, they can travel easily with their preferred transportation modes. Such a relocation of rural dissonants could be realized by enlarging the supply of dwellings in urban areas, which will reduce the price of houses in urban neighborhoods. This reduction of residential prices can convince them to live in urban neighborhoods. The high prices of urban dwellings are often found to be an important reason for rural dissonants to reside in rural neighborhoods, despite their urban preferences. However, the decision to relocate is not obvious, since a relocation generally brings along considerable monetary as well as nonmonetary costs. Furthermore, new urban residents might maintain their travel behavior they developed while residing in a rural neighborhood. Car use can become so deep-rooted that they will rarely use the alternative transportation modes available in urban neighborhoods. The reduction of dwelling prices can also have the undesirable effect of attracting rural consonants to urban neighborhoods, who will probably hang on to car use (Kitamura et al., 1997; Schwanen and Mokhtarian, 2005a). Offering additional dwellings can be realized in two ways. An important differentiation can be made between the adaptation of an existing neighborhood and the realization of a new neighborhood. Adapting an existing neighborhood implies the risk of increasing the dissonance among the initial inhabitants of that neighborhood. For example, rural consonants might become more mismatched after measures resulting in an increasing density in their current neighborhood. This dissonance will only reduce gradually when the former residents relocate or adapt their attitudes to the 
new situation and when new residents will be attracted to the new built environment. Only in that situation a change in travel behavior can be noticed. In contrast, the realization of a new neighborhood will lead to a residential location choice according to the new situation. Hence, there will be no time period with a raised residential dissonance (Kitamura et al., 1997; van Wee et al., 2002).

By offering dwellings in urban surroundings, Flanders tries to restrict urban sprawl. The 'Spatial Structure Plan for Flanders' strives for at least $60 \%$ of additional dwellings in urban areas (Ministerie van de Vlaamse Gemeenschap, 1997). However, our results suggest that the relocation of rural dissonants to urban neighborhoods would only have a slight effect on travel behavior in Flanders. Not only the extent of the residential neighborhood type dissonance is important, neighborhood satisfaction also needs to be taken into account (Fig. 3). Especially rural dissonants with a strong to very strong difference between the actual and preferred residential neighborhood and a low to nonexistent neighborhood satisfaction will consider to move. Mismatched rural residents with a weak or moderate difference between the actual and preferred residential neighborhood will probably not consider it necessary to move. Mismatched rural residents with a high to very high neighborhood satisfaction will also not tend to relocate easily. Only $4.3 \%$ of all mismatched respondents will probably take a relocation into consideration. Hence, it seems better to adjust existing neighborhoods instead of realizing new neighborhoods; new neighborhoods would probably only attract a limited amount of rural residents. Increasing density and diversity in existing neighborhoods seems a better option. This should best be realized together with changing attitudes. Otherwise it might be possible that the residential dissonance will only get larger for the original residents.

Mismatched rural residents in Flanders however, will probably not make considerably more use of car alternatives after their relocation to an urban residential neighborhood. Since they succeed well in realizing their preferred travel behavior, a relocation of rural dissonants to urban neighborhoods will most likely only have little effect on travel behavior.

A second major opportunity to reduce residential dissonance is by adapting attitudes, so that they better match with the actual residential neighborhood. A change in attitude of urban dissonants to a more positive attitude toward alternative modes of transportation will decrease the residential dissonance and can have a positive effect on travel behavior. If these residents have a bigger affinity toward public transit, walking and bicycling, they will most likely travel less by car and use the alternative modes available in urban areas more frequently. Moreover, a more positive attitude of rural dissonants toward car alternatives can cause a larger residential dissonance, whereby the chance of a relocation to urban neighborhoods increases. Such a change in attitudes could be realized by improving the image of alternative transportation modes, e.g., by underlining the positive effects of these modes for the environment and personal health (Kitamura et al., 1997; Van Acker et al., 2011a). Another option is to improve the image of the city. Because of the noise- and traffic nuisance and the lack of green spaces, the city is for most people not an ideal place to reside. Since 2000 Flanders conducts a city-policy. This policy aims to enlarge the attraction of the city. By underlining positive aspects of the city (such as many job opportunities, cultural and leisure activities) it attempts to counteract the urban exodus, especially of young households with 
children (http://www.thuisindestad.be/). However, an improved image of car alternatives and the city will not necessarily lead to a higher use of car alternatives. Due to strong habitual patterns, attitude and effective behavior do not always match ('value-action' gap) (Ajzen, 1991; Shove, 2010). An individual who prefers to walk, for example, may use the car for short distances due to strong general car habit (Verplanken et al., 1997). A temporary change in service level of a transportation system can help change travel mode choice. Offering free public transit on selected days or implementing temporary road pricing, for instance, may trigger lasting behavioral changes of habitual car drivers to public transit use, walking or bicycling (Fujii and Kitamura, 2003).

The adaptation of attitudes can best be realized with urban dissonants with a weak to moderate difference between the actual and preferred residential neighborhood and a high to very high neighborhood satisfaction (Fig. 3). Mismatched urbanites with a strong to very strong residential dissonance will have difficulties to transform their strong rural land use preferences into urban land use preferences. Mismatched urbanites with a low to a nonexistent neighborhood satisfaction will rather try to reduce their residential dissonance by relocating, instead of changing their attitudes. The group of urban dissonants whereby residential dissonance can relatively easy be reduced by changing attitudes amounts $21.7 \%$ of all mismatched respondents.

\begin{tabular}{|c|c|c|c|c|c|c|c|c|}
\hline & \multicolumn{2}{|c|}{$\begin{array}{c}\text { Very high } \\
\text { satisfaction }\end{array}$} & \multicolumn{2}{|c|}{$\begin{array}{c}\text { High } \\
\text { satisfaction }\end{array}$} & \multicolumn{2}{|c|}{$\begin{array}{c}\text { Low } \\
\text { satisfaction }\end{array}$} & \multicolumn{2}{|c|}{$\begin{array}{c}\text { No } \\
\text { satisfaction }\end{array}$} \\
\hline & $N$ & $\%$ & $N$ & $\%$ & $N$ & $\%$ & $N$ & $\%$ \\
\hline U. d. (weak difference) & 26 & 3.2 & 54 & 6.7 & 59 & 7.3 & 35 & 4.3 \\
\hline U. d. (moderate difference) & 39 & 4.8 & 57 & 7.0 & 65 & 8.0 & 31 & 3.8 \\
\hline U. d. (strong difference) & 20 & 2.5 & 49 & 6.1 & 63 & 7.8 & 27 & 3.3 \\
\hline U. d. (very strong difference) & 29 & 3.6 & 39 & 4.8 & 38 & 4.7 & 20 & 2.5 \\
\hline R. d. (very strong difference) & 8 & 1.0 & 4 & 0.5 & 8 & 1.0 & 6 & 0.7 \\
\hline R. d. (strong difference) & 8 & 1.0 & 16 & 2.0 & 18 & 2.2 & 3 & 0.4 \\
\hline R. d. (moderate difference) & 9 & 1.1 & 11 & 1.4 & 12 & 1.5 & 6 & 0.7 \\
\hline R. d. (weak difference) & 10 & 1.2 & 23 & 2.8 & 11 & 1.4 & 5 & 0.6 \\
\hline \multicolumn{9}{|l|}{$\square$ Changing attitudes (easy) } \\
\hline \multicolumn{9}{|l|}{$\square$ Changing attitudes (difficult) } \\
\hline \multicolumn{9}{|l|}{$\square$ Relocating (easy) } \\
\hline$\square$ Relocating (difficult) & & & & & & & & \\
\hline
\end{tabular}

Fig. 3. Possibility of mismatched respondents to reduce their dissonance ${ }^{7}$

\footnotetext{
${ }^{7}$ U.d. = Urban dissonant; R.d. = Rural dissonant
} 
However, a reduction of residential dissonance of urban residents will only have a slight influence on travel behavior. Flemish urban dissonants have difficulties in realizing their preferred travel behavior. They travel more with car alternatives than desired, since car use is limited in urban areas. If their attitudes toward urban land use and car alternatives improve, they probably will make even less use of the car and make more use of the available alternatives. Since urban dissonants in Flanders already frequently use car alternatives, the effect of changes in attitude will only have a limited influence on travel behavior.

In sum, changing attitudes seems a better way to reduce residential dissonance in Flanders than offering affordable dwellings in urban areas. Increasing density and diversity in existing neighborhoods can have a positive effect on the residential dissonance, but only if attitudes are changed as well. Constructing new neighborhoods will only have little impact. However, it can be noted that even an adjustment of attitudes will merely have a modest influence on travel behavior. It should be noted that other factors, such as cultural differences and the functioning of the housing market, might also matter. However, no specific conclusions on these factors can be drawn from our sample and results. Further research might therefore take such factors into account as well.

\section{Conclusion}

According to our study, more than half of the participating respondents do not live in their preferred residential neighborhood. This dissonance influences travel behavior of mismatched respondents. Urban dissonants face difficulties in travelling with their preferred car. Car use seems to be highly influenced by the physical structure of the residential neighborhood. Rural dissonants, on the other hand, are capable of using car alternatives quite easily. The use of these transportation modes seems less dependent of the residential neighborhood, but mainly of preferences toward residential neighborhood and travel modes. The applied land use planning and mobility policy can mainly explain these findings. Flanders is a highly urbanized region with a widespread spatial development and limited open spaces. The resulting large share of urban residents and large share of residents with rural land use preferences cause a considerable residential dissonance. Relatively short travel distances and a cheap and spatially widespread public transit can explain why rural dissonants are capable of travelling with their preferred travel modes. Increasing congestion and parking problems discourage car use for urban dissonants. Rural dissonants are consequently more capable of realizing their preferred travel behavior than urban dissonants. Reducing residential dissonance by offering affordable dwellings in urban neighborhoods will only have a limited effect, since the group of rural dissonants that considers moving to urban neighborhoods is small. Changing attitudes of urban dissonants, by improving the image of car alternatives and the city as a dwelling-place, together with a temporary change in service level of a transportation mode, is a better way to reduce residential dissonance. A more positive attitude toward urban land use and car alternatives will stimulate them to make more use of car alternatives. However, the influence on travel behavior will be limited since urban dissonants are already often forced to travel by these alternatives. 


\section{References}

Ajzen, I., 1991. The theory of planned behavior. Organizational Behavior and Human Decision Processes 50(2), 179-211.

Anable, J., 2005. Complacent Car Addicts or Aspiring Environmentalists? Identifying travel behaviour segments using attitude theory. Transport Policy 12(1), 65-78.

Arnau, R.C., 1998. Second-order factor analysis: methods and interpretation. Proceedings of the Annual Meeting of the Southwestern Psychological Association, New Orleans.

Bagley, M.N., Mokhtarian, P.L., 2002. The impact of residential neighborhood type on travel behavior: a structural equations modeling approach. The Annals of Regional Science 36(2), 279-297.

Bhat, C.R., Guo, J.Y., 2007. A comprehensive analysis of built environment characteristics on household residential choice and auto ownership levels. Transportation Research B 41(5), 506-526.

Cao, X., Mokhtarian, P.L., Handy, S.L., 2007. Do changes in neighborhood characteristics lead to changes in travel behavior? A structural equations modeling approach. Transportation 34(5), 535-556.

Cervero, R., 1996. Traditional neighborhoods and commuting in the San Francisco Bay Area. Transportation 23(4), 373-394.

Chen, C., Gong, H., Paaswell, R., 2008. Role of the built environment on mode choice decisions: additional evidence on the impact of density. Transportation 35(3), 285-299.

Friedman, B., Gordon, S.P., Peers, J.B., 1994. Effect of neotraditional neighborhood design on travel characteristics. Transportation Research Records 1466, 63-70.

Fujii, S., Kitamura, R., 2003. What does a one-month free bus ticket do to habitual drivers? Transportation 30(1), 81-95.

Handy, S.L., Cao, X., Mokhtarian, P.L., 2005. Correlation or causality between the built environment and travel behavior? Evidence from Northern California. Transportation Research D 10(6), 427-444.

Kitamura, R., Mokhtarian, P.L., Laidet, L., 1997. A micro-analysis of land use and travel in five neighborhoods in the San Francisco Bay Area. Transportation 24(2), 125-158.

Ministerie van de Vlaamse Gemeenschap, 1997. Ruimtelijk Structuurplan Vlaanderen. Brussel: Ministerie van de Vlaamse Gemeenschap.

Mokhtarian, P.L., Cao, X., 2008. Examining the impacts of residential self-selection on travel behaviour: a focus on methodologies. Transportation Research B 42(3), 204-228. 
Molin, E., Oppewal, H., Timmermans, H., 1999. Group-based versus individual-based conjoint preference models of residential preferences: a comparative test. Environment and Planning A 31(11), 1935-1947.

Naess, P., 2005. Residential location affects travel behavior - but how and why? The case of Copenhagen metropolitan area. Progress in Planning 63(2), 167-257.

Oh, J.H., 2003. Social bonds and the migration intentions of elderly urban residents: The mediating effect of residential satisfaction. Population Research and Policy Review 22(2), $127-146$.

Schwanen, T., Mokhtarian, P.L., 2004. The extent and determinants of dissonance between actual and preferred residential neighborhood type. Environment and Planning B 31(5), 759784.

Schwanen, T., Mokhtarian, P.L., 2005a. What affects commute mode choice: neighbourhood physical structure or preferences toward neighborhoods? Journal of Transport Geography 13(1), 83-99.

Schwanen, T., Mokhtarian, P.L., 2005b. What if you live in the wrong neighborhood? The impact of residential neighbourhood type dissonance on distance traveled. Transportation Research D 10(2), 127-151.

Shove, E., 2010. Beyond the ABC: climate change policy and theories of social change. Environment and Planning A 42(6), 1273-1285.

Speare, A., 1974. Residential satisfaction as an intervening variable in residential mobility. Demography 11(2), 173-188.

Steg, L., 2005. Car use: lust and must. Instrumental, symbolic and affective motives for car use. Transportation Research Part A 39(2-3), 147-162.

Steg, L., Vlek, C., Slotegraaf, G., 2001. Instrumental-reasoned and symbolic-affective motives for using a motor car. Transportation Research Part F 4(3), 151-169.

Thomas, L.A., 1995. The use of second-order factor analysis in psychological research. Proceedings of the Annual Meeting of the Southwestern Psychological Association, San Antonio.

Van Acker, V., Mokhtarian, P.L., Witlox, F., 2011a. Going soft: on how subjective variables explain modal choices for leisure travel. European Journal of Transport and Infrastructure Research 11(2), 115-146.

Van Acker, V. Mokhtarian, P.L., Witlox, F., 2011b. Refining the lifestyle concept in travel behaviour research. Mobilities (submitted for publication).

Van der Haegen, H., Van Hecke, E., Juchtmans, G., 1996. De Belgische stadsgewesten in 1991. Brussel: Nationaal Instituut voor de Statistiek, Statistische Studiën, Volume 104. 
van Wee, B., 2009. Self-selection: a key to a better understanding of location choices, travel behaviour and transport externalities? Transport Reviews 29(3), 279-292.

van Wee, B., Holwerda, H., van Baren, R., 2002. Preferences for modes, residential location and travel behaviour: the relevance for land-use impacts on mobility. European Journal of Transport and Infrastructure Research 2(3/4), 305-316.

Verhetsel, A., Witlox, F., 2006. Children and housing: 'Only the best is good enough'. Some evidence from Belgium. Childhood. A Global Journal of Child Research 13(2), 205-224.

Verplanken, B., Aarts, H., Van Knippenberg, A., 1997. Habit, information acquisition, and the process of making travel mode choices. European Journal of Social Psychology 27(5), 539-560. 